Article

\title{
Extraction and Physicochemical Characterization of Chitin Derived from the Asian Hornet, Vespa velutina Lepeletier 1836 (Hym.: Vespidae)
}

\author{
Xesús Feás ${ }^{1, *}$, M. Pilar Vázquez-Tato ${ }^{2}{ }^{\mathbb{D}}$, Julio A. Seijas ${ }^{2}{ }^{\mathbb{D}}$, Anna Pratima G. Nikalje ${ }^{3}$ and \\ Francisco Fraga-López ${ }^{4, *(D)}$ \\ 1 Academy of Veterinary Sciences of Galicia, Edificio EGAP, Rúa Madrid, No. 2-4, 15707 Santiago de \\ Compostela, (A Coruña), Spain \\ 2 Departamento de Química Orgánica, Facultad de Ciencias, Universidad of Santiago De Compostela, Alfonso \\ X el Sabio, 27002 Lugo, Spain; pilar.vazquez.tato@usc.es (M.P.V.-T.); julioa.seijas@usc.es (J.A.S.) \\ 3 Department of Chemistry, Wilson College, Girgaon Chawpatty, Mumbai 400007, Maharashtra, India; \\ annapratimanikalje@gmail.com \\ 4 Departamento de Física Aplicada Departamento de Física Aplicada, Facultad de Ciencias, Universidad de \\ Santiago de Compostela, Avda. Alfonso X El Sabio s/n, 27002 Lugo, Spain \\ * Correspondence: xesusfeas@gmail.com (X.F.); francisco.fraga@usc.es (F.F.-L.)
}

Academic Editor: Julio A. Seijas Vázquez

Received: 31 December 2019; Accepted: 14 January 2020; Published: 17 January 2020

check for updates

\begin{abstract}
Fifteen years ago, at least one multimated female yellow-legged Asian hornet (Vespa velutina Lepeletier 1836) arrived in France, which gave rise to a pan-European invasion. In this study, the isolation and characterization of chitin (CHI) that was obtained from Vespa velutina $\left(\mathrm{CHI}_{\mathrm{VV}}\right)$ is described. In addition, an easy procedure is carried out to capture the raw insect, selectively and with high rates of success. The chitin contents of dry VV was observed to be $11.7 \%$. Fourier transform infrared spectroscopy (FTIR), solid-state NMR (ssNMR), elemental analysis (EA), scanning electron microscopy (SEM), and thermogravimetric analysis (TG) characterized the physicochemical properties of $\mathrm{CHI}_{\mathrm{VV}}$. The obtained $\mathrm{CHI}_{\mathrm{VV}}$ is close to pure $(43.47 \% \mathrm{C}, 6.94 \% \mathrm{H}$, and $6.85 \% \mathrm{~N})$, and full acetylated with a value of $95.44 \%$. Additionally, lifetime and kinetic parameters such as activation $\mathrm{E}$ and the frequency factor A using model-free and model-fitting methods, were determined. For $\mathrm{CHI}_{\mathrm{VV}}$ the solid state mechanism that follows the thermodegradation is of type F2 (random nucleation around two nuclei). The invasive Asian hornet is a promising alternative source of $\mathrm{CHI}$, based on certain factors, such as the current and probable continued abundance of the quantity and quality of the product obtained.
\end{abstract}

Keywords: chitin; Vespa velutina; Asian hornet; polymer; invasive species; insects

\section{Introduction}

The chitin (CHI) is the most abundant biopolymer in nature, behind only cellulose. Structurally, it is the simplest of the glycosaminoglycans, being a $\beta(1 \rightarrow 4)$ linked linear homopolymer of $\mathrm{N}$-acetylglucosamine (GlcNAc, $\left[\mathrm{C}_{8} \mathrm{H}_{13} \mathrm{O}_{5} \mathrm{~N}\right] \mathrm{n}$, where $\mathrm{n} \gg 1$ ). It primarily exists in alga [1,2], fungi [3], arthropods (crab, shrimp, crayfish, and insects) [4], copepod, and mollusks (squid) [5]. It was cited that approximately 100 billion tons of $\mathrm{CHI}$ are produced, as a major structural component in the exoesqueleton from the above organisms [6], being around 80,000 $t$ obtained per year from the marine by-products by industry for commercial exploitation. [7].

$\mathrm{CHI}$ is usually converted into chitosan and partially acetylated chitosan oligomers (COS) by hydrolysis of the acetamide groups due to its poor solubility in most organic solvents as well as water. A soluble material can be obtained in aqueous acid medium, with three attractive reactive sites 
enabling modification, including one primary amine and two primary or secondary hydroxyl groups per glucosidic unit [8].

This polycationic polymer can be processed into several forms, and chemically or enzymatically modified, with a definite chemical composition and ordered structure [9]. Definitively, they have emerged as a new class of physiological materials of highly sophisticated functions, being referred the $\mathrm{CHI}$ as the "undisputed biomolecule of great potential" [10].

The great variety of applications of chitosan in the field of biomaterials is due to its excellent properties when interacting with the human body: bioactivity [11], antimicrobial and antifungal activity [12,13], immunostimulation [14], chemotactic action, enzymatic biodegradability, mucoadhesion, and epithelial permeability [15], which supports the adhesion and proliferation of different cell types [16]. With the above properties, CHI derivatives serve a broad range of applications and these materials have advanced at a dramatic pace into many fields, including skin, wound, and burn management [17]; drug delivery and pharmaceutical applications [18]; tissue engineering [19]; dentistry [20]; plant science and agriculture [21]; veterinary science [22]; cosmetics and cosmeceutical [23]; food and nutraceuticals [24]; and, paper industry [25], among others.

Despite the widespread occurrence of $\mathrm{CHI}$, until now the main commercial sources have been crab, prawn, lobster, krill, and shrimp shells. The resulting CHI needs to be graded in terms of purity and colour, since residual protein and pigment can cause problems for further utilization, especially for biomedical products [26].

Two new sources as fungi and insect species have been recently researched as an alternative origin for these functional materials in order to expand the chitin-chitosan based source and obtain a better material and more consistent quality $[3,7,27-31]$. The insect and fungal biopolymers have many features that can make them more advantageous than those biopolymers from seafood waste origin [32], due to potential advantages in terms of homogenous polymer length, high degree of deacetylation and solubility over the current marine source [7]. The needs in new sources are very acute since the traditional methods of $\mathrm{CHI}$ by catches of shellfish and complex selection procedures of desired product are largely limited. Use of insects for $\mathrm{CHI}$ manufacture is grounded by economic benefit, being much cheaper and easier than by the treating of crustaceans or mushrooms [33].

The yellow-legged Asian hornet (Vespa velutina Lepeletier 1836 (Hymenoptera: Vespidae)) is naturally distributed in Southeast Asia, India, and China; however, fifteen years ago, at least one multimated female yellow-legged Asian hornet arrived in France. The species has subsequently expanded its range and it is now presently recognized as a pan-European threat after being detected in Spain (2010), Portugal (2011), Belgium (2011), Italy (2012), Germany (2014), and the Netherlands (2018), as well as on islands such as Majorca in the Balearic Islands (2015), England, and the Channel Islands (2016) [34]. The large numbers of Vespa velutina that were captured for the control of this specie can provide an abundant and stable source for the production of $\mathrm{CHI}[35,36]$.

In the present work, physicochemical properties of the chitin isolated from Vespa velutina were determined for the first time. First, a procedure is presented to selectively catch the invasive insect. Secondly, the CHI was purified while using alkaline and acid treatments, followed by decolourization and, finally, the obtained Vespa velutina (VV) chitin were characterized by Fourier transform infrared spectroscopy (FTIR), elemental analysis (EA), scanning electron microscopy (SEM), and thermogravimetric analysis (TGA). Additionally, kinetic parameters such as activation $\mathrm{E}$ and the frequency factor A using model-free methods given by Kissinger, Flynn Wall, and Ozawa (FWO), Coats Redfern, were determined. The results that were obtained in the present work allow for us to consider the invasive species Vespa velutina as a large-scale and perspective source of chitin/chitosan obtaining. 


\section{Results and Discussion}

\subsection{Insect Source and Chitin Yield}

Approximately 2,289 insects with a total weight of $824.8 \mathrm{~g}$ were caught and dried to constant weight. A total of $235.9 \mathrm{~g}$, or 28.6 per cent of the weight of the fresh material, of dry insect bodies were obtained. Therefore, the percent moisture loss of the insects, based on percent of the original weight, was $71.4 \%$.

The Asian hornet is an insect hunter, specializing in honeybees. Unlike in its area of origin, where the Asian honeybee (Apis cerana) has developed defence mechanisms against its attacks, the European honeybee (Apis mellifera) does not show effective defence behaviour. The hives are brutally attacked by the Asian hornet coinciding with the development peak of its colony, and the need for more protein to feed its larvae. From this point of view, apiaries are a suitable and selective site, as the obtained results show, to obtain the raw insects. The traps placed show exclusively captures of VV and not of other not-target insects. The results are a reflection of VV activity and the relative abundance of the species present at the time that the traps were allocated.

The chitin content of VV was recorded to be $11.7 \%$ on a dry basis. Dry insects from previous studies have been determined to have $\mathrm{CHI}$ in the range of $10-36 \%$, and these organisms have been reviewed and suggested to be used as alternative sources for $\mathrm{CHI}$ production [9]. The CHI content of the shells of commercially used organisms, such as crayfish, shrimp, and crap, was referred to be around $20 \%$ [28].

\subsection{Spectroscopic Chitin Analysis}

Three different allomorphic forms of chitin, as $\alpha, \beta$, and $\gamma$ are known from the literature. FT-IR spectroscopy is one of the fastest and simplest techniques used to determine allomorphic form of chitin. The amide I band of the $\alpha$ form gives two sharp bands at 1652 and $1620 \mathrm{~cm}^{-1}$, whereas the $\beta$ form only presents a single band around $1640 \mathrm{~cm}^{-1}$ due to the hydrogen bonds between the molecules [37], as known from many reported studies regarding FT-IR spectrum (Figure 1) of $\alpha$ - and $\beta$-chitin.

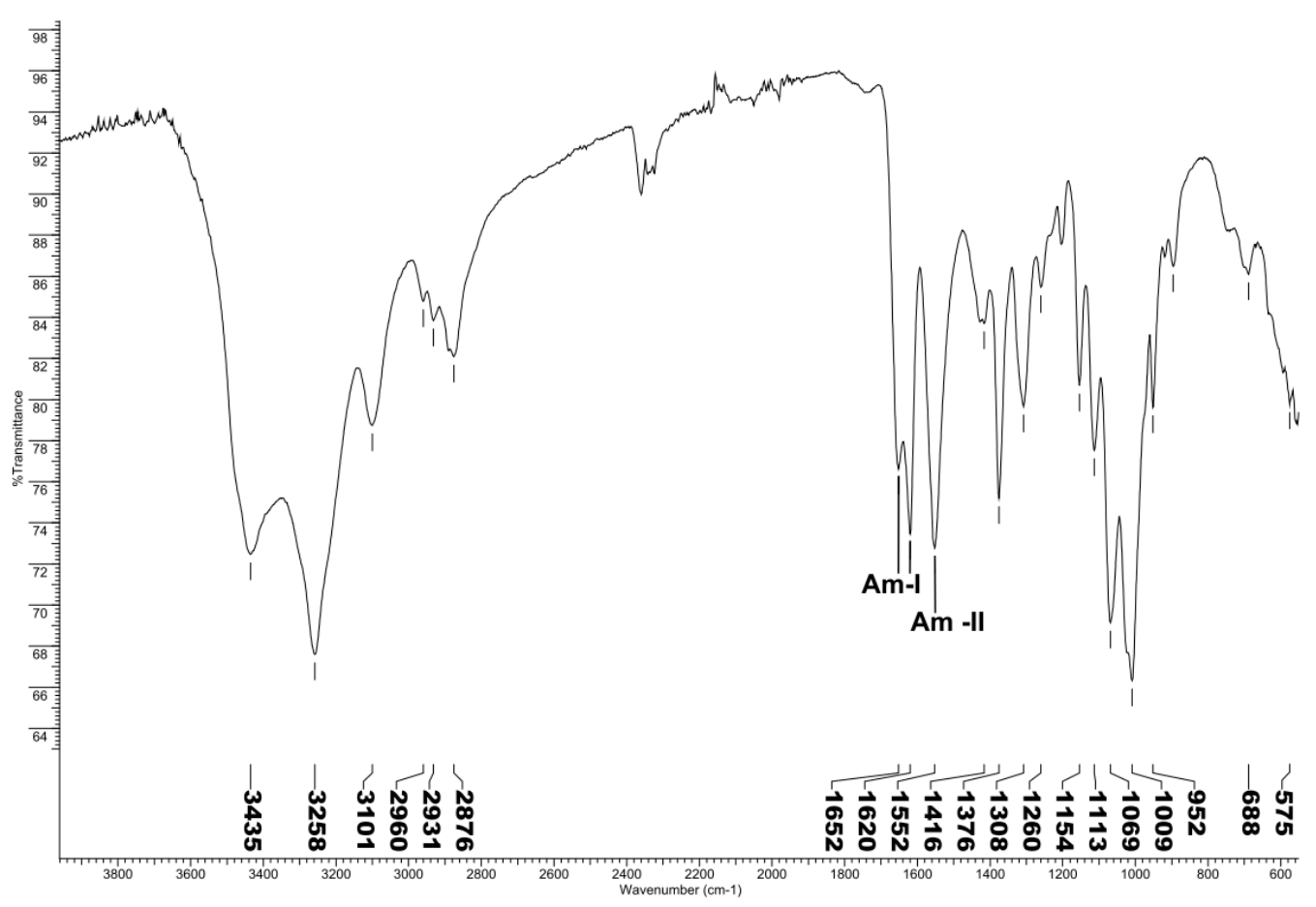

Figure 1. Fourier-transform infrared spectroscopy (FT-IR) spectrum data of chitin extracted from Vespa velutina. 1652 and 1620 amide I (Am-I), 1552 amide II (Am-II) characteristic of $\alpha$-chitin. 
Solid-state CP-MAS ${ }^{13} \mathrm{C}$ NMR is known to be very sensitive to changes in the local order structure. Solid NMR experiments combine cross-polarization for the sensitivity enhancement of the signal-to-noise ratio with dipolar decoupling for the removal of dipolar interactions from protons and magic-angle spinning for high resolution of chemical shifts. From NMR spectra (Figure 2), $\alpha$-chitin and $\beta$-chitin are easily distinguished. Two signals around 75 and $82 \mathrm{ppm}$ have been assigned to C3, and the C5 carbon atoms in $\alpha$-chitin are sharply resolved; the signals for $\beta$-chitin appear as a singlet [38].

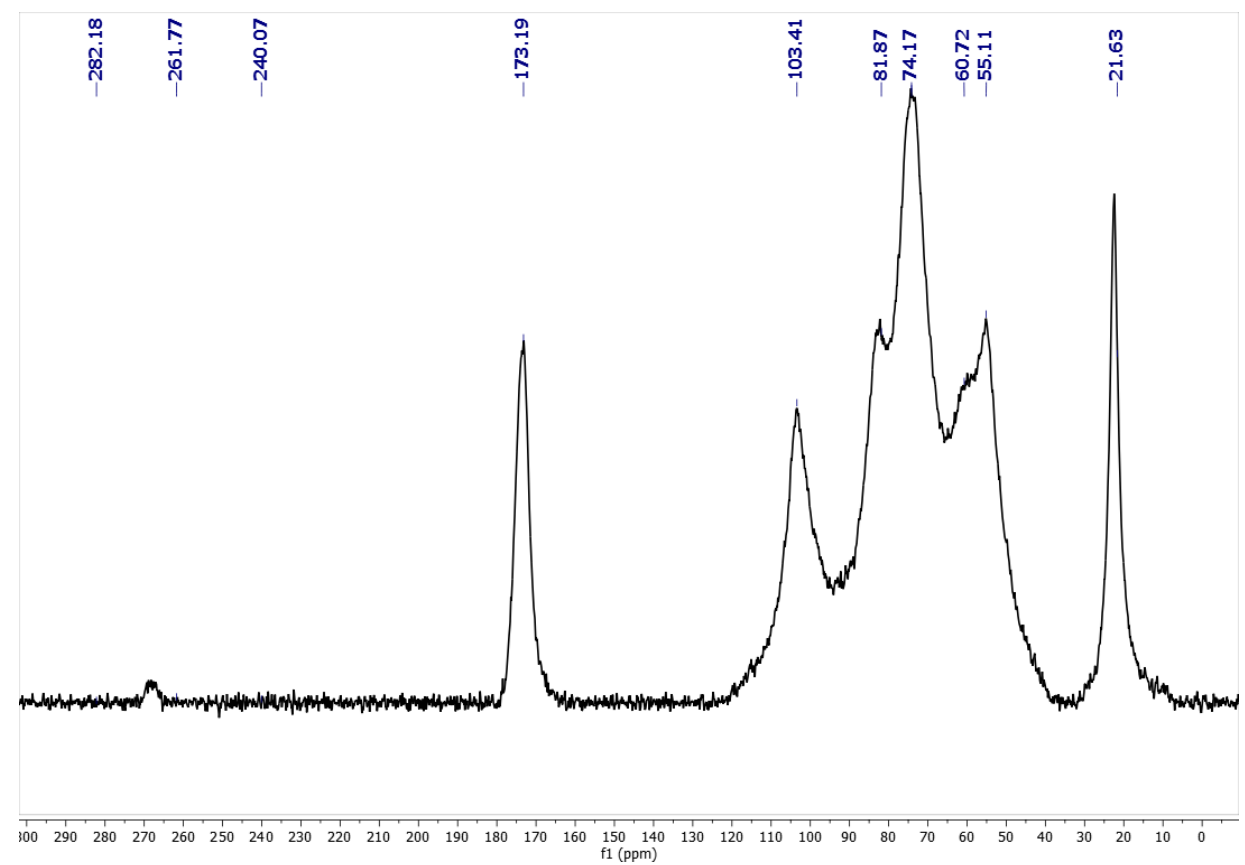

Figure 2. Solid-state CP-MAS ${ }^{13} \mathrm{C}$ NMR of chitin extracted from Vespa velutina. ${ }^{13} \mathrm{C}$ NMR $(126 \mathrm{MHz}): \delta$ $267.96,173.17,104.12,82.74,75.34,60.34,55.94,22.79$.

\subsection{Elemental analysis (EA) and Degree of Acetylation (DA)}

Table 1 shows the results of the elemental composition measurements and the theoretical values for $\mathrm{CHI}_{\mathrm{VV}}$, including carbon, nitrogen, hydrogen, as well as \%CHN contents and $\mathrm{C} / \mathrm{N}$ ratio. Acetylation degree (DA) of $\mathrm{CHI}_{\mathrm{VV}}$ was calculated while using the elemental analysis results. $\mathrm{CHN}$ analysis provides a quick and inexpensive method to check chitin purity, and in conjunction with other techniques, allows for the characterisation of the biopolymer obtained. The chemical composition of polymers is connected with the chemical, physical, and mechanical properties.

Table 1. Elemental composition measurements and theoretical values for chitin from Vespa velutina.

\begin{tabular}{ccccccc}
\hline & \% C & \% H & \% N & \% CHN & C/N & DA\% \\
\hline Vespa velutina chitin & 43.47 & 6.94 & 6.85 & 57.26 & 6.35 & 95.44 \\
Theoretical value of chitin & 47.29 & 6.40 & 6.90 & 60.59 & 6.86 & 100 \\
Found-Theoretical & -3.82 & 0.54 & -0.05 & -3.33 & -0.51 & -4.56 \\
\hline
\end{tabular}

Elemental analysis revealed that $\mathrm{CHI}_{\mathrm{VV}}$ consisted of $43.47 \% \mathrm{C}, 6.94 \% \mathrm{H}$, and $6.85 \% \mathrm{~N}$, totalling \% $\mathrm{CHN}$ of 57.26. Experimental $\mathrm{C} / \mathrm{N}$ for $\mathrm{CHI}_{\mathrm{VV}}$ was 6.35 , being the theoretical value expected 6.86 . The DA was calculated to be $95.44 \%$. The results showed that $\mathrm{C}, \mathrm{N}$ and $\% \mathrm{CHN}$ contents were found minor that theoretical values. Only experimental $\mathrm{H}$ for $\mathrm{VV}$ chitin was found to be higher than the theoretical value expected $6.40 \%$. Based on the above results, $\mathrm{CHI}_{\mathrm{VV}}$ is close to pure and full acetylated. In previous researches using related insects, the \% of $\mathrm{C}, \mathrm{H}$, and $\mathrm{N}$ content in $\mathrm{CHI}$ were recorded as 46.62, 6.42, and 6.85 for Vespa crabro; 46.01, 6.71, and 6.34 for Vespa orientalis [28], and 45.5, 6.3, and 6.49 for Vespa crabro, respectively [31]. 
The determination of the $\mathrm{C}, \mathrm{H}$, and $\mathrm{N}$ content of $\mathrm{CHI}$ is highly recommended for the control quality of the polymer that was obtained after purification from raw material. Moreover, these parameters can give us more information regarding the chemical process used to purificate CHI from a matrix. For example, $\mathrm{N}$ in insects mostly occurs in protein and $\mathrm{CHI}$, which combine in different proportions to produce the insect exoskeleton or cuticule. The $\mathrm{N}$ content is also a measure of the protein amount that is still present in CHI, not being eliminated in the chemical extraction process [39]. Chitin isolates typically have $\mathrm{N}$ content about $7 \%$ [40]. DA values that are higher than $100 \%$ indicate that some minerals are still present in the CHI structure, not being fully eliminated in the demineralisation step.

\subsection{Scanning Electron Microscopy (SEM)}

Scanning electron microscopy is a highly suitable method for observing the structure of polymers, in general [41-43], and anatomical variation in CHI organization in insect cuticles, in particular [44]. Figure $3 \mathrm{a}-\mathrm{d}$ shows the diverse nano and micro scale organization of the $\mathrm{CHI}_{\mathrm{VV}}$.

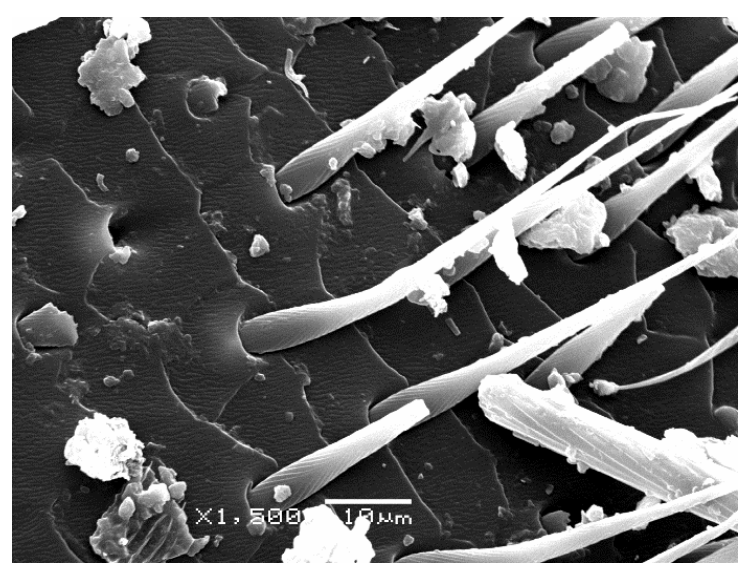

(a)

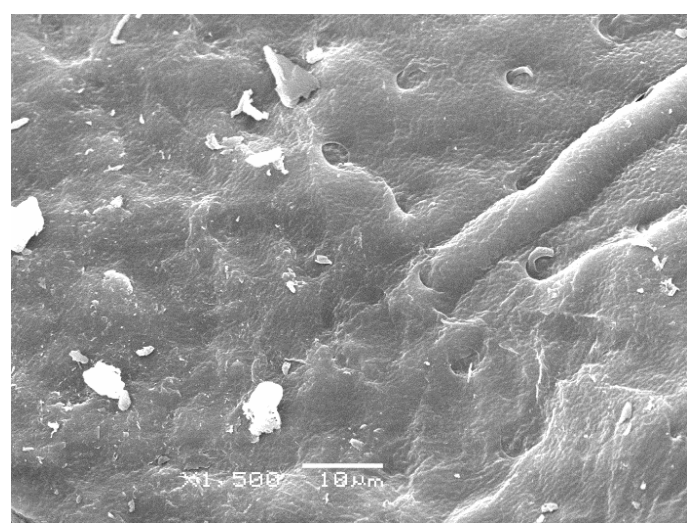

(c)

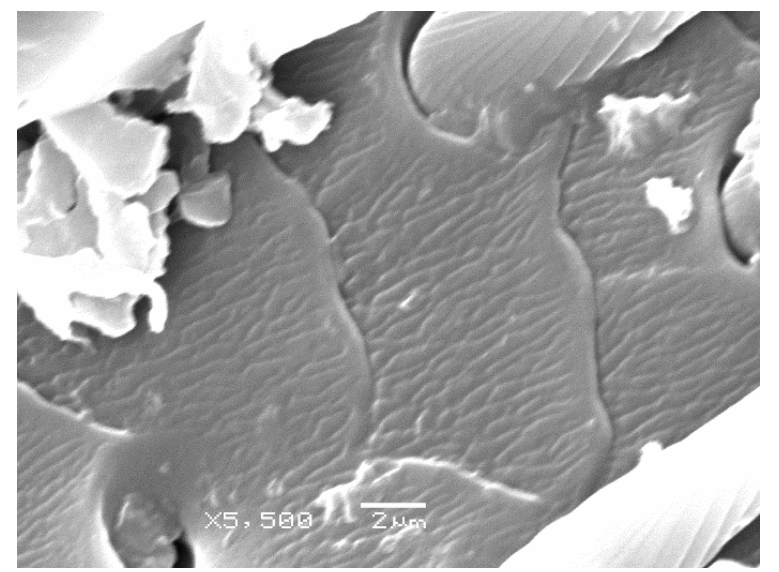

(b)

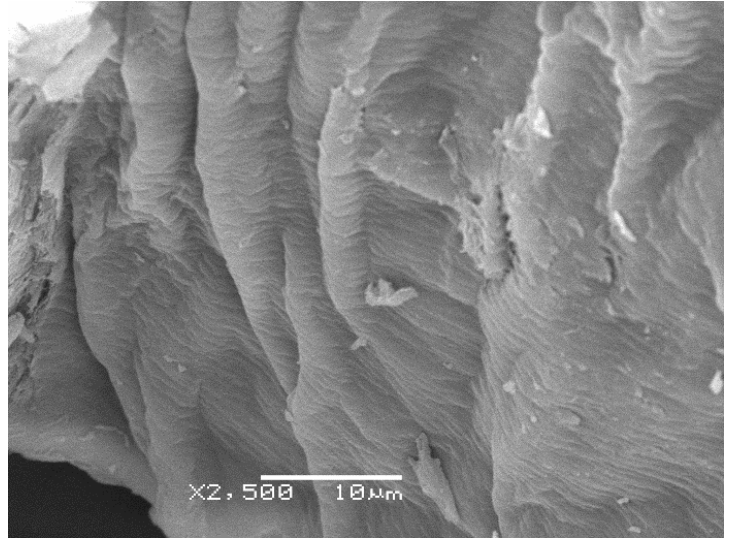

(d)

Figure 3. Scanning electron microscopy (SEM) pictures of chitin isolated from Vespa velutina. (a) magnification $\times 1500$ (scale bar $=10 \mu \mathrm{m}$ ); (b) magnification $\times 5500$ (scale bar $=2 \mu \mathrm{m}$ ); (c) magnification $\times 1500$ (scale bar $=10 \mu \mathrm{m}$ ) and $(\mathrm{d})$ magnification $\times 2500($ scale bar $=10 \mu \mathrm{m})$.

Morphologies that were identified using SEM and classificated as (1) microporous smooth surface, (2) fish scale shaped nano fibrous surface, (3) adherent fibres with nano pores, and (4) separated fibres with nano pores were reported previously for Vespa crabro [31]. Similar structures were found in the present work for $\mathrm{CHI}_{\mathrm{VV}}$. 


\subsection{Thermogravimetric Analysis (TG)}

Thermogravimetric analysis is the most commonly used technique for characterizing the decomposition and thermal stability of materials under certain conditions. In addition, kinetic parameters can be extracted from thermogravimetric data and predicted half-life $[45,46]$. The main advantage lies in the simplicity and sensitivity of the technique and in the extensive information that was obtained from a thermogram. The experiments were performed at different heating rates ( $\beta$ ) between 5 and $25{ }^{\circ} \mathrm{C} / \mathrm{min}$. with increments of $10^{\circ} \mathrm{C} / \mathrm{min}$., since a priori, with a low heating rate, the evolution of thermal degradation occurs with greater independence of the measurement method, without necessarily being affected by the test.

In dynamic tests, mass loss is carried out according to a controlled temperature program. The dynamic methods are divided into differential or integral methods, as they are based on the general velocity equation or its integrated form, respectively. Figure 4 shows the thermodegradation of $\mathrm{CHI}_{\mathrm{VV}}$ at different heating rates.

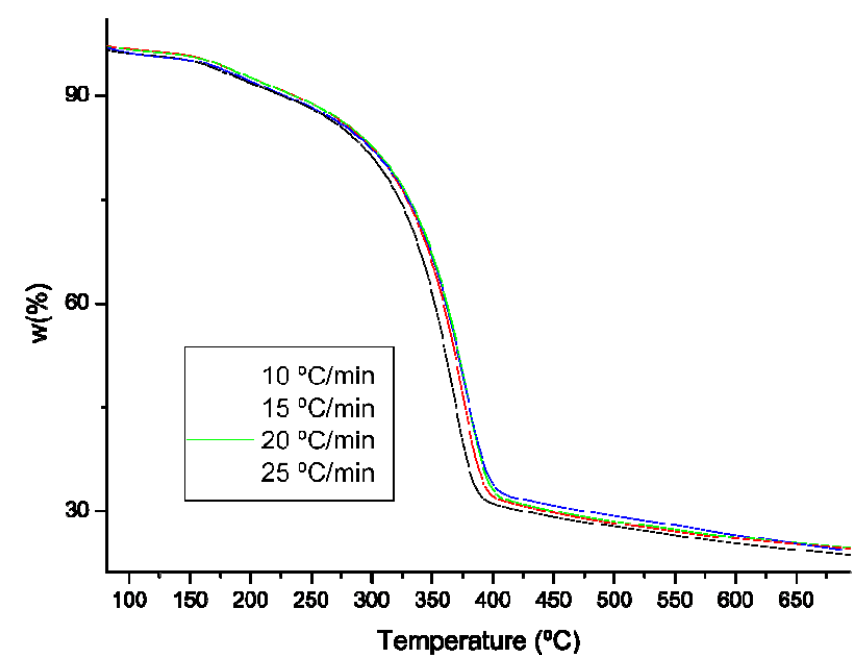

Figure 4. Experimental thermogravimetric (TG) curves at different heating rates of chitin isolated from Vespa velutina.

The curves have a single-type thermodegradation in a single stage. The inflection points of the curves are taken as a characteristic point for thermodegradation and for the analysis of the different degradation methods. We can observe that, for $\mathrm{CHI}_{\mathrm{VV}}$, this point occurs at the temperature of $367^{\circ} \mathrm{C}$. Around $700{ }^{\circ} \mathrm{C}$, there is only a $20 \%$ residue left. Previous research, where GlcNAc was pyrolized at 200 ${ }^{\circ} \mathrm{C}$ for $30 \mathrm{~min}$., identified pyrazines, pyridines, pyrroles, and furans as thermal degradation products, ranking compound 3-acetamido-5-acetylfuran first [47].

According with the equation calculation process (see Equation (14) in the Material and Methods Section) if $\ln \left(\beta / T_{m}{ }^{2}\right)$ is represented against the inverse of the temperature, the activation energy can be obtained from the slope of the line. Table 2 shows the values that were used in the calculation of the activation energy for $\mathrm{CHI}_{\mathrm{VV}}$. The activation energy obtained is $128.6 \mathrm{~kJ} / \mathrm{mol}$.

Table 2. Inflection point temperatures at different rates for chitin.

\begin{tabular}{cc}
\hline $\mathbf{B}\left({ }^{\circ} \mathbf{C} / \mathbf{m i n}\right)$ & $\mathbf{T}\left({ }^{\circ} \mathbf{C}\right)$ \\
\hline 5 & 363 \\
10 & 367.8 \\
15 & 369.3 \\
20 & 376.3 \\
\hline
\end{tabular}


In this way, $\log \beta$ can be represented against the inverse of the absolute temperature and obtain the activation energy $(E)$ as the slope of the linear adjustment. Table 3 shows the activation energy values that were obtained for $\mathrm{CHI}_{\mathrm{VV}}$ with different degrees of degradation $(\alpha=0.20,0.25,0.30$, and 0.35$)$.

Table 3. Degradation energies at different conversions for chitin obtained from Vespa velutina.

\begin{tabular}{cc}
\hline $\boldsymbol{\alpha}$ & $\mathbf{E}_{\mathbf{a}}(\mathbf{k J} / \mathbf{m o l})$ \\
\hline 5 & 117.8 \\
10 & 118.9 \\
15 & 114.1 \\
20 & 105.5 \\
\hline
\end{tabular}

The average value of the activation energy is $114.1 \mathrm{~kJ} / \mathrm{mol}$ for chitin, being this value very close to those that were obtained by the Kissinger method.

According with the equation calculation process (see Equations (27) and (28) in the Material and Methods Section), for each of the solid state reaction mechanisms, one can define a $g(\alpha)$, at each of the heating rates, which will be used for conversions between 0.2 and 0.35 . Once the functions $g(\alpha)$ are known, we can make the linear adjustment to obtain the activation energies and their correlation coefficients at each heating rate (Table 4 ).

Table 4. Degradation energies at different heating rates and different thermodegradation mechanisms for Vespa velutina chitin.

\begin{tabular}{|c|c|c|c|c|}
\hline Solid State Process & Mechanism & $5^{\circ} \mathrm{C} / \mathrm{min}$ & $10^{\circ} \mathrm{C} / \mathrm{min}$ & $15^{\circ} \mathrm{C} / \mathrm{min}$ \\
\hline $\begin{array}{l}\text { Nucleation and growth (Avrami } \\
\text { Equation (1)) }\end{array}$ & $\mathrm{A}_{2}$ & 35.2 & 53.6 & 44.7 \\
\hline $\begin{array}{l}\text { Nucleation and growth (Avrami } \\
\text { Equation }(2))\end{array}$ & $\mathrm{A}_{3}$ & 16.9 & 33.8 & 11.3 \\
\hline $\begin{array}{l}\text { Nucleation and growth (Avrami } \\
\text { Equation (3)) }\end{array}$ & $\mathrm{A}_{4}$ & 6.5 & 17.4 & 5.9 \\
\hline $\begin{array}{l}\text { Phase boundary controlled reaction } \\
\text { (one-dimensional movement) }\end{array}$ & $\mathrm{R}_{1} / \mathrm{F}_{0}$ & 67.1 & 53.7 & 73.6 \\
\hline $\begin{array}{l}\text { Phase boundary controlled reaction } \\
\text { (contracting area) }\end{array}$ & $\mathrm{R}_{2}$ & 77.2 & 62.8 & 82.7 \\
\hline $\begin{array}{l}\text { Phase boundary controlled reaction } \\
\text { (contracting volume) }\end{array}$ & $\mathrm{R}_{3}$ & 80.8 & 66.07 & 85.9 \\
\hline One-dimensional diffusion & $\mathrm{D}_{1}$ & 187.7 & 161.8 & 181.5 \\
\hline Two-dimensional diffusion & $\mathrm{D}_{2}$ & 200.9 & 173.7 & 193.4 \\
\hline Three-dimensional diffusion (Jander eq.) & $\mathrm{D}_{3}$ & 215 & 186.6 & 202.4 \\
\hline $\begin{array}{l}\text { Three-dimensional diffusion } \\
\text { (Ginstling-Brounshtein eq.) }\end{array}$ & $\mathrm{D}_{4}$ & 205.6 & 177.9 & 197.6 \\
\hline $\begin{array}{l}\text { Random nucleation with one nucleus on } \\
\text { the individual particle }\end{array}$ & $\mathrm{F}_{1}$ & 88 & 72.5 & 92.36 \\
\hline $\begin{array}{l}\text { Random nucleation with two nuclei on the } \\
\text { individual particle }\end{array}$ & $\mathbf{F}_{2}$ & 111.3 & 93.5 & 113.3 \\
\hline $\begin{array}{l}\text { Random nucleation with three nuclei on the } \\
\text { individual particle }\end{array}$ & $\mathbf{F}_{3}$ & 137.1 & 116.7 & 102.6 \\
\hline
\end{tabular}

From these data and, when comparing with the activation energy obtained by the Kissinger and Flynn_Wall-Ozawa methods, we can highlight that, for $\mathrm{CHI}_{\mathrm{VV}}$, the solid state mechanism that follows the thermodegradation is of type F2 (random nucleation around two nuclei). 


\subsection{Prediction of the Average Lifetime Considering the Reaction Mechanism}

The philosophy of the prediction of the average lifetime is based on identifying the critical reaction that limits the life of a material, studying the kinetics of the said reaction at high temperatures, where the reaction is faster. Finally, the expressions of the kinetic properties are used and the kinetics are extrapolated to much longer reaction times at much lower temperatures, at which the sample will be in service. Obviously, we can also find the shortest life times by extrapolating the kinetics at higher temperatures.

The half-life can be determined once the reaction mechanism is known, without using the expression of $g(\alpha)$ of the corresponding solid-state mechanism, from the activation energy and the pre-exponential factor that were calculated from the Flynn-Wall-Ozawa method. The velocity constant can be deduced from the Arrhenius equation as a function of temperature. The study of the thermodegradation kinetics of $\mathrm{CHI}_{\mathrm{VV}}$ confirms a mechanism F2. The half-life at different temperatures for $\mathrm{CHI}_{\mathrm{VV}}$ can be observed in Table 5 .

Table 5. Half-life for chitin samples extracted from Vespa velutina at different temperatures.

\begin{tabular}{cc}
\hline $\mathbf{T}\left({ }^{\circ} \mathbf{C}\right)$ & Time (years) \\
\hline 20 & 285 \\
30 & 61 \\
40 & 14 \\
50 & 4 \\
60 & 1 \\
70 & $0.3(110$ days $)$ \\
80 & $0.1(37$ days $)$ \\
90 & $0.03(12$ days $)$ \\
100 & 0.01 (5 days) \\
\hline
\end{tabular}

The prediction of the average lifetime is a technique that is usually used in the industry to know the probable behaviour of new materials over time [48]. The obtained results show that $\mathrm{CHI}_{\mathrm{VV}}$ should not be used at temperatures above $60^{\circ} \mathrm{C}$, since its half-life would be only one year. In studies such as those we present at work, it is accepted that thermogravimetric analysis, with its kinetic parameters, is sufficient for determining the lifetime of the material. This time is considered when $5 \%$ of the initial mass [49] has been lost or when $5 \%$ of the conversion [50] has been reached in a thermogravimetric experiment.

\section{Materials and Methods}

\subsection{Sampling of Insects}

During September 2017, adult Vespa velutina specimens were obtained while using a trapping method at an apiary in Viveiro (Galicia, Spain), as shown in Figure 5. The beehives $(n=6)$ had a frontal protective module, as a grid, which prevents the entry of the Asian hornet into the hive. The traps $(n=12)$ used for capturing the insects consisted of a 15 litre plastic box with a clip on lid and carry handle $($ volume $=15 \mathrm{l}$; width $=36.5 \mathrm{~cm}$; depth $=28.5 \mathrm{~cm}$; height $=18.5 \mathrm{~cm}$ ). A total of four holes were made on the sides of the container for insects to enter. In each hole, a $5 \mathrm{~cm}$ snap on roller was inserted with $1 \mathrm{~cm}$ of the body outside the box. The attractant used consisted of half blueberry juice, half dark brown bee, $r$ and wax obtained from honeybee combs. After one week in the field, the content inside the traps were removed, and the obtained insects were sent to the laboratory. 


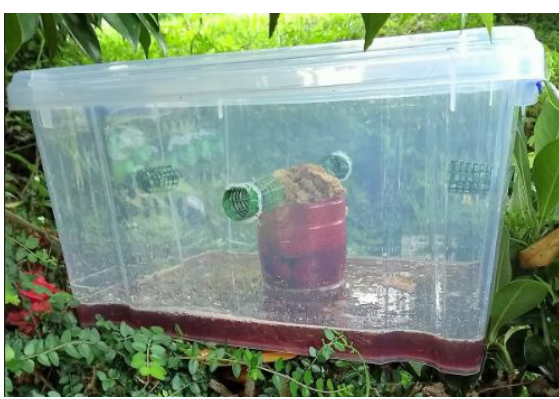

(a)

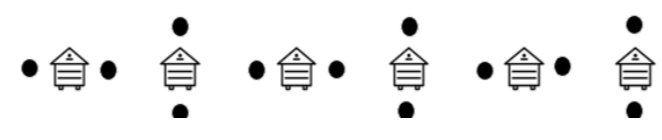

(b)

Figure 5. (a) The trap used to catch the Vespa velutina; (b) The (black dots) show the distribution of the traps in the apiary.

\subsection{Insects Pre-treatment}

The insects were washed under the flow of tap water using a metal strainer to remove any remaining matter from the attractant in the trap and paper dried. The number of captured individuals were counted and weighed, obtaining the insect total number (ITN) and insect wet weight (IWW). Afterwards, the insects were oven dried for two days at $70^{\circ} \mathrm{C}$, weighed, and insect dry weight (IDW) was recorded. The difference between IWW and IDW was used to determine the percent moisture of the sample, based on percent of the original weight, as follows:

$$
\text { Moisture }(\text { wet basis })=[\mathrm{IWW}-\mathrm{IDW}) \mathrm{IWW}] \times 100
$$

Subsequently, oven dried insects were milled using a GRINDOMIX GM 200 (Retsch GmbH, Haan, Germany) and stored in airtight containers in a desiccator.

\subsection{Extraction of Chitin}

Chitin extraction was carried out while using the conventional chemical method that was reported by Kaya et al. [28,31], with modifications. In brief, this involved three major steps, i.e., demineralization, deproteination, and decolourization, carried out as follows.

\subsubsection{Demineralisation}

This step involved the removal of mineral matter from the insects. The sample (5 g) was treated in $1 \mathrm{M} \mathrm{HCl}$ solution $(100 \mathrm{~mL})$ at $50{ }^{\circ} \mathrm{C}$ for $3 \mathrm{~h}$ while using a heating magnetic stirrer (Heildoph, Schawabach, Germany). After this process, the samples were washed with distilled water to remove residual $\mathrm{HCl}$. This was repeated until neutral $\mathrm{pH}$ was reached in wash supernatant.

\subsubsection{Deproteinization}

For deproteinization, the demineralizated samples were treated in $1 \mathrm{M} \mathrm{NaOH}$ solution $(100 \mathrm{~mL})$ at $60^{\circ} \mathrm{C}$ for $8 \mathrm{~h}$. After this process, the samples were washed with distilled water to remove residual $\mathrm{HCl}$. This was repeated until the neutral $\mathrm{pH}$ was reached in wash supernatant.

\subsubsection{Decolourization}

For the removal of the pigments, the demineralizated and deproteinizated samples were mixed with $100 \mathrm{~mL} \mathrm{1 \%}$ sodium hypochlorite solution, at room temperature. The mixture was agitated with a magnetic stirrer for $1 \mathrm{~h}$ to decolourize it. Following the filtration process, the samples were thoroughly washed in distilled water before being placed in an oven at $50^{\circ} \mathrm{C}$ for one week. The finally obtained chitin was weighed (CHIw) and then stored in desiccator, until further analysis. 


\subsection{Chitin Obtained}

The percentage yield of the $\mathrm{CHI}$ obtained was calculated as follow:

$$
\text { Yield of chitin }=(\mathrm{CHIw}-\mathrm{IDW}) \times 100
$$

\subsection{Chitin Spectroscopic Characterisation}

Fourier-transform infrared spectroscopy (FTIR) was performed while using a Nicolet ${ }^{\mathrm{TM}}$ iS10 spectrometer (Thermo Scientific, Madison, USA) that was equipped with a $\mathrm{KBr}$ beam splitter and fitted with an attenuated total reflection (ATR) device (Golden Gate, $45^{\circ}$ single-bounce diamond anvil, Specac, UK). Optical of the spectrometer and ATR device were both purged while using dry air. The samples for FTIR analysis were prepared by grinding the chitin with powdered $\mathrm{KBr}$, in the ratio of 1:5 (Sample: $\mathrm{KBr})$. The samples were scanned at room temperature $\left(25 \pm 1{ }^{\circ} \mathrm{C}\right)$ and spectral data between 550 and $4000 \mathrm{~cm}^{-1}$ was obtained by collecting 32 scans at $4 \mathrm{~cm}^{-1}$ resolution. Corrections for background absorbance and sampling depth of the ATR method were applied.

\subsection{Solid-state NMR (ssNMR) Analysis}

Solid-state CP-MAS 13C NMR experiment was performed using a spectrometer Varian VNMRS-500-WB (Agilent Technologies, Palo Alto, CA, USA) at $126 \mathrm{MHz}$, while using adamantine as calibration sample.

\subsection{Chitin Thermogravimetric Analysis (TGA)}

Measurements of thermogravimetric analysis (TGA) were performed on a TGA/DSC 1 START $_{e}$ SYSTEM (Metter-Toledo AG, Schwerzenbach, Switzerland), while using alumina crucibles under a stream of $\mathrm{N}_{2}$. The system was operated in the dynamic mode in the temperature range $100-900{ }^{\circ} \mathrm{C}$, at different heating rates: $10,15,20$, and $25^{\circ} \mathrm{C}$. The sample size was approx. $5 \mathrm{mg}$. The results were processed using the Mettler STARe 9.01 software (Metter-Toledo AG, Schwerzenbach, Switzerland).

\subsubsection{Kinetic Methods}

Most of the methods of kinetic analysis are based on the hypothesis that, from a simple thermogram, important parameters, such as activation energy, pre-exponential factor, and reaction order, are obtained. Decomposition is one of the phenomena that can occur when a sample undergoes a heating process. A kinetic study is necessary in order to determine the kinetic parameters that characterize this change [51]. For this, the conversion $\alpha$ is previously defined as:

$$
\alpha=\frac{m_{i}-m}{m_{i}-m_{f}}
$$

$\mathrm{m}_{\mathrm{i}}$ and $\mathrm{m}_{\mathrm{f}}$ are, respectively, the initial and final mass at a given instant.

The changes in sample mass can be evaluated as a function of temperature (dynamic method) or as a function of time at constant temperature (isothermal method). In dynamic methods, the temperature increases, generally linearly, according to a heating program.

We can conclude that thermogravimetric analysis, in either of its two methods (dynamic or isothermal), relates conversion, time, and temperature since we have defined conversion based on mass loss, and, consequently, a model could be "designed" Kinetic to describe the thermal degradation of the system. The mathematical model that has been taken into account expresses the reaction rate of the solid state as:

$$
\frac{d \alpha}{d t}=k(T) \cdot f(\alpha)
$$

Being $\alpha$ the degree of conversion, $k(T)$ the velocity constant, and $f(\alpha)$ the dependence function of the decomposition mechanism. 
Since the change in mass is a function of temperature, its effect is introduced through the Arrhenius equation:

$$
k(T)=A \cdot e^{-\frac{E}{R T}}
$$

where $\mathrm{A}$ is the pre-exponential factor, $\mathrm{E}$ is the activation energy, and $\mathrm{R}$ is the gas constant.

In this type of study, the use of the Arrhenius equation is questioned, although it should be noted that parameters $\mathrm{A}$ and $\mathrm{E}$ are determined experimentally, and its theoretical interpretation is very difficult [52]. By combining these two equations, the reaction velocity equation can be written in the form:

$$
\frac{d \alpha}{d t}=A \cdot e^{-\frac{E}{R T}} \cdot f(\alpha)
$$

It should be noted that the velocity also depends on the partial pressure of the gases originating in the thermodegradation (product gases), so this expression should also include a pressure function [52]. However, in most cases, a constant inert gas flow is operated at constant pressure, so that the influence of the product gases can be neglected. If the temperature of the sample constantly changes, that is, if we are working in a dynamic regime, the variation in the degree of conversion can be analysed as a function of the temperature, which, in turn, is dependent on the heating time. In these cases the speed equation is written, as follows:

$$
\frac{d \alpha}{d t}=\frac{d \alpha}{d T} \cdot \frac{d T}{d t}=\beta \cdot \frac{d \alpha}{d T}
$$

In which $\alpha=d T / d t$ is defined as the heating rate.

If we clear $d \alpha / d T$ :

$$
\frac{d \alpha}{d T}=\frac{1}{\beta} \cdot \frac{d \alpha}{d t}
$$

The combination of expressions (6) and (9) leads to:

$$
\frac{d \alpha}{d T}=\frac{1}{\beta} \cdot A \cdot e^{-\frac{E}{R T}} \cdot f(\alpha)
$$

Separating variables and integrating this equation from an initial temperature $\mathrm{T}_{0}$, which corresponds to a conversion $\alpha_{0}$, to a temperature Tp with a conversion $\alpha \mathrm{p}$ we obtain an expression:

$$
\int_{\alpha_{0}}^{\alpha} \frac{d \alpha}{f(\alpha)}=\frac{A}{\beta} \int_{0}^{T} e^{-\frac{E}{R T}} d T
$$

For small initial temperatures, it is reasonable to assume that $\alpha_{0}=0$ and admitting that there is no reaction between 0 and $T_{0}$ [53], the integral conversion function, $g(\alpha)$, can be defined in this way:

$$
g(\alpha)=\int_{0}^{\alpha_{p}} \frac{d \alpha}{f(\alpha)}=\frac{A}{\beta} \int_{0}^{T} e^{-\frac{E}{R T}} d T
$$

where $\mathrm{A}, \mathrm{E}$, and $\mathrm{g}(\alpha)$ or $\mathrm{f}(\alpha)$ must be experimentally determined.

In a high number of chemical compounds, the degradation process behaves as a sigmoidal or decelerative function. The expressions of $g(\alpha)$ for the different solid-state mechanisms are successfully used in the estimation of reaction mechanisms from dynamic curves [52,54].

\subsubsection{Differential Method}

The analysis of mass changes, which is produced as a result of varying the heating rate, is the basis of the most powerful differential methods for the study and determination of kinetic parameters. One of the most used is the Kissinger method [55], which uses the inflection point of the thermogram to determine the activation energy. 
Kissinger differentiated the general speed equation and obtained:

$$
\frac{d^{2} \alpha}{d t^{2}}=\frac{E \beta}{R T^{2}} \cdot \frac{d \alpha}{d t}+A \cdot e^{-\frac{E}{R T}} \cdot f^{\prime}(\alpha) \cdot \frac{d \alpha}{d t}=\left[\frac{E \beta}{R T^{2}}+A \cdot e^{-\frac{E}{R T}} \cdot f^{\prime}(\alpha)\right] \frac{d \alpha}{d t}
$$

Particularizing the above equation for the point of inflection at the temperature $T_{m}$, at which the maximum degradation occurs:

$$
0=\frac{E \beta}{R T_{m}^{2}}+A \cdot e^{-\frac{E}{R T_{m}}} \cdot f^{\prime}\left(\alpha_{m}\right)
$$

Rearranging and taking logarithms, the equation takes the form:

$$
\ln \left(\frac{\beta}{T_{m}^{2}}\right)=-\frac{E}{R T_{m}}+\ln \left[f^{\prime}\left(\alpha_{m}\right) \cdot \frac{A R}{E}\right]
$$

\subsubsection{Integral Methods}

\section{Flynn-Wall-Ozawa Method}

In cases where the sample is heated at a constant speed [56,57], it is verified that:

$$
\frac{d \alpha}{d t}=\frac{d \alpha}{d T} \cdot \frac{d T}{d t}=\beta \cdot \frac{d \alpha}{d T}
$$

As already described in the previous section, equation 11 reached a series of considerations. The resolution of this integral is greatly simplified by entering the variable $x$ defined as:

$$
x=\frac{E}{R T}
$$

Clearing $\mathrm{T}$ and differentiating,

$$
\begin{gathered}
T=\frac{E}{R x} \\
d T=-\frac{E}{R x^{2}} d x
\end{gathered}
$$

As we introduce a new variable, we must also change the limits of integration:

$$
\begin{gathered}
T \rightarrow 0 \Rightarrow x \rightarrow \infty \\
T \rightarrow T \Rightarrow x \rightarrow \frac{E}{R T}
\end{gathered}
$$

To be able to rewrite the integral, as follows:

$$
g(\alpha)=\int_{\infty}^{x} \frac{A}{\beta} \cdot\left(-\frac{E}{R}\right) \cdot \frac{e^{-x}}{x^{2}} \cdot d x=\frac{A E}{\beta R} \cdot p(x)
$$

where $p(x)=\int_{\infty}^{0} \frac{e^{-x}}{x^{2}} d x$. This new integral can be evaluated for several values of $\mathrm{x}$ and in the literature there are several approaches $[58,59]$. The Schlömlich expansion is one of the most commonly used series for the estimation of $\mathrm{p}(\mathrm{x})$, which was used with good results by Doyle.

$$
p(x)=\frac{e^{-x}}{(1+x) x}=\left(1-\frac{1}{x+2}+\frac{2}{(x+2)(x+3)}-\frac{3}{(x+2)(x+3)(x+4)}+\ldots\right)
$$

Doyle considers it to be sufficient to take only the first two terms of each series. With what:

$$
p(x)=\frac{e^{-x}}{x(x+2)}
$$


Finding that for $\mathrm{x}>20$ and taking logarithms could express $\mathrm{p}(\mathrm{x})$ as:

$$
\log _{10} p(x) \approx-2.315-0.457 x
$$

Flynn and Wall, on the one hand, and Ozawa on the other, developed a method in which they used the Doyle approach [60] to, without knowing the reaction order, be able to determine the activation energy. According to this, equation 18 is transformed into:

$$
g(\alpha)=\frac{A E}{\beta R} \cdot \frac{e^{-x}}{x(x+2)}
$$

If we take logarithms and reorder:

$$
\log \beta=\log \frac{A E}{R g(\alpha)}-2.315-\frac{0.457 E}{R T}
$$

\section{Coats-Redfern Method}

To solve the temperature integral, Coats and Redfern [61] suggest an asymptotic expansion, so that the integral equation is transformed into:

$$
g(\alpha)=\frac{A R T^{2}}{\beta E}\left(1-\frac{2 R T}{E}\right) e^{-\frac{E}{R T}}
$$

Taking logarithms:

$$
\ln g(\alpha)=\ln \frac{A R}{\beta E}+2 \ln T+\ln \left(1-\frac{2 R T}{E}\right)-\frac{E}{R T}
$$

Assuming that $\ln (1-2 \mathrm{RT} / \mathrm{E})$ tends to zero for the working conditions used $(x>20)$, we can write:

$$
\ln \frac{g(\alpha)}{T^{2}}=\ln \frac{A R}{\beta E}-\frac{E}{R T}
$$

\subsubsection{Prediction of the Average Lifetime Considering the Reaction Mechanism}

Taking that the half-life is defined as the time necessary to reach $5 \%$ of the conversion into account, the equation for determining the half-life once the reaction mechanism is known is as follows, introducing in $\mathrm{g}(\alpha)$ the solid state equations corresponding to $\mathrm{CHI}_{\mathrm{VV}}$ :

$$
t=\frac{g(0.05)}{k}
$$

\subsection{Elemental Analysis}

The total carbon, nitrogen, and hydrogen in $\mathrm{CHI}$ were estimated while using $\mathrm{C} \mathrm{H} \mathrm{N}$ elemental analyser (Flash EA 1112 Series, Thermo Finnigan, Italy), which consisted of the system unit, a MAS 200 autosampler for solid samples, and a Windows compatible computer with Eager 300 software. The equipment was calibrated and standardized while using BBOT Standard $\{2,5-b i s$ (5-tert-butyl-benzoxazol-2-yl)-thiopen, $\mathrm{C}_{26} \mathrm{H}_{26} \mathrm{~N}_{2} \mathrm{O}_{2} \mathrm{~S}$, Thermo Finnigan, Italy)\}. The minimum detection limit for $\mathrm{C}, \mathrm{N}$, and $\mathrm{H}$ was calculated to be $0.08 \%$.

\subsection{Degree of Acetylation (DA)}

The acetylation degree (DA) of the chitin that was obtained from Asian hornet samples was calculated according to [62] while using the elemental analysis results

$$
\mathrm{DA}=[(\mathrm{C} / \mathrm{N}-5.145) / 1.72] \times 100
$$




\subsection{Scanning Eectron Microscopy (SEM)}

The morphology of chitin obtained was observed while using SEM (JEOL JSM-6360LV, Tokyo, Japan). The samples required a gold ion coating. First, a sample was mounted on metallic studs with double-sided conductive tape. Gold ion coating was then applied with a sputter coater (Bal-tec SCD 050, GmbH, Witten, Germany) for $60 \mathrm{~s}$ under vacuum at a current intensity of $60 \mathrm{~mA}$. The acceleration voltage during SEM scanning was $20 \mathrm{kV}$.

\section{Conclusions}

To the best of our knowledge, this is the first time that the isolation and characterization of chitin that was obtained from Vespa velutina is described. The dry weight chitin content of V. velutina was $11.7 \%$. The surfaces structures of the Asian hornet chitin samples showed different morphology that mainly consisted of nanofibers and nanopores. Elemental analysis revealed that chitin from $V$. velutina consisted of $43.47 \% \mathrm{C}, 6.94 \% \mathrm{H}$, and $6.85 \% \mathrm{~N}$. The acetylation degree value was calculated as $95.44 \%$. The study of the thermodegradation kinetics of $V$. velutina chitin confirms a mechanism F2 (random nucleation around two nuclei). The Asian hornet is a promising alternative source of chitin based on certain factors, such as the current and probable continued abundance of this invasive species and the trapping procedure proposed and employed, as well as the quality of the product obtained.

Author Contributions: Conceptualization, X.F.; methodology, X.F., M.P.V.-T., J.A.S., A.P.G.N, F.F.-L.; writing一original draft preparation, X.F.; writing-review and editing, X.F., M.P.V.-T., J.A.S., A.P.G.N., F.F.-L. All authors have read and agreed to the published version of the manuscript.

Funding: This research was funded by DEPUTACION DE A CORUÑA and MINISTERIO DE ECONOMÍA, INDUSTRIA Y COMPETITIVIDAD (Spain), Project MAT2017-86109-P.

Acknowledgments: X.F. would like to acknowledge Jose María Vázquez for obtaining the insect samples and Rebecca Jane Charles for his diligent proofreading of this paper. Also, special thanks to Murat Kaya, from the Department of Biotechnology and Molecular Biology (Aksaray University, Turkey) for helpful advice and encouragement.

Conflicts of Interest: The authors declare no conflict of interest. The funders had no role in the design of the study; in the collection, analyses, or interpretation of data; in the writing of the manuscript, or in the decision to publish the results.

\section{References}

1. Rahman, M.; Halfar, J. First evidence of chitin in calcified coralline algae: New insights into the calcification process of Clathromorphum compactum. Sci. Rep. 2015, 4, 6162. [CrossRef]

2. Rahman, M.A.; Halfar, J.; Adey, W.H.; Nash, M.; Paulo, C.; Dittrich, M. The role of chitin-rich skeletal organic matrix on the crystallization of calcium carbonate in the crustose coralline alga Leptophytum foecundum. Sci. Rep. 2019, 9, 11869. [CrossRef]

3. Baeva, E.; Bleha, R.; Lavrova, E.; Sushytskyi, L.; Čopíková, J.; Jablonsky, I.; Klouček, P.; Synytsya, A. Polysaccharides from Basidiocarps of Cultivating Mushroom Pleurotus ostreatus: Isolation and Structural Characterization. Molecules 2019, 24, 2740. [CrossRef]

4. Peniche, C.; Argüelles-Monal, W.; Goycoolea, F.M. Chapter 25-Chitin and Chitosan: Major Sources, Properties and Applications. In Monomers, Polymers and Composites from Renewable Resources. Elsevier Sci. 2008, 10, 517-542.

5. Duan, B.; Huang, Y.; Lu, A.; Zhang, L. Recent Advances in Chitin Based Materials Constructed via Physical Methods. Prog. Polym. Sci. 2018, 82, 1-33. [CrossRef]

6. Muxika, A.; Etxabide, A.; Uranga, J.; Guerrero, P.; De la Caba, K. Chitosan as a bioactive polymer: Processing, properties and applications. Int. J. Biol. Macromol. 2017, 105, 1358-1368. [CrossRef] [PubMed]

7. Ghormade, V.; Pathan, E.K.; Deshpande, M.V. Can fungi compete with marine sources for chitosan production? Int. J. Biol. Macromol. 2017, 104, 1415-1421. [CrossRef]

8. Samal, S.K.; Dash, M.; Van Vlierberghe, S.; Kaplan, D.; Chiellini, E.; Blitterswijk, C.; Moroni, L.; Dubruel, P. Cationic polymers and their therapeutic potential. Chem. Soc. Rev. 2012, 41, 7147-7194. [CrossRef] [PubMed] 
9. Leke-Aladekoba, A. Comparison of Extraction Methods and Characterization of Chitin and Chitosan with Antimicrobial Properties from Black Soldier Fly (Hermatia Illucens) Meal. Ph.D. Thesis, Dalhousie University Halifax, Halifax, NS, Canada, November 2018.

10. Tharanathan, R.N.; Kittur, F.S. Chitin-The undisputed biomolecule of great potential. Crit. Rev. Food Sci. Nutr. 2003, 43, 61-87. [CrossRef]

11. Sultankulov, B.; Berillo, D.; Sultankulova, S.; Tokay, T.; Saparov, A. Progress in the Development of Chitosan-Based Biomaterials for Tissue Engineering and Regenerative Medicine. Biomolecules 2019, 9, 470. [CrossRef]

12. Deka, S.R.; Sharma, A.K.; Kumar, P. Cationic polymers and their self-assembly for antibacterial applications. Curr. Top. Med. Chem. 2015, 15, 1179-1195. [CrossRef]

13. Verlee, A.; Mincke, S.; Steven, C.V. Recent developments in antibacterial and antifungal chitosan and its derivatives. Carbohydr. Polym. 2017, 164, 268-283. [CrossRef]

14. Torres, F.G.; Troncoso, O.P.; Pisani, A.; Gatto, F.; Bardi, G. Natural Polysaccharide Nanomaterials: An Overview of Their Immunological Properties. Int. J. Mol. Sci. 2019, 20, 5092. [CrossRef] [PubMed]

15. Ways, T.M.; Lau, W.M.; Khutoryanskiy, V.V. Chitosan and Its Derivatives for Application in Mucoadhesive Drug Delivery Systems. Polymers 2018, 10, 267. [CrossRef] [PubMed]

16. Laroche, C.; Delattre, C.; Mati-Baouche, N.; Salah, R.; Violeta Ursu, A.; Moulti-Mati, F.; Michaud, P.; Guillaume, P. Bioactivity of Chitosan and Its Derivatives. Curr. Org. Chem. 2018, 22, 641-647. [CrossRef]

17. Danti, S.; Trombi, L.; Fusco, A.; Azimi, B.; Lazzeri, A.; Morganti, P.; Coltelli, M.; Donnarumma, G. Chitin Nanofibrils and Nanolignin as Functional Agents in Skin Regeneration. Int. J. Mol. Sci. 2019, 20, 2669. [CrossRef] [PubMed]

18. Shariatinia, Z. Pharmaceutical applications of chitosan. Adv. Colloid Interface Sci. 2019, 263, 131-194. [CrossRef]

19. Ahsan, S.M.; Thomas, M.; Reddy, K.K.; Sooraparaju, S.G.; Asthana, A.; Bhatnagar, I. Chitosan as biomaterial in drug delivery and tissue engineering. Int. J. Biol. Macromol. 2018, 110, 97-109. [CrossRef]

20. Aguilar, A.; Zein, N.; Harmouch, E.; Hafdi, B.; Bornert, F.; Offner, D.; Clauss, F.; Fioretti, F.; Huck, O.; Benkirane-Jessel, N.; et al. Application of Chitosan in Bone and Dental Engineering. Molecules 2019, 24, 3009. [CrossRef]

21. Malerba, M.; Cerana, R. Recent Applications of Chitin- and Chitosan-Based Polymers in Plants. Polymers 2019, 11, 839. [CrossRef]

22. Mohan, K.; Ravichandran, S.; Muralisankar, T.; Uthayakumar, V.; Chandirasekar, R.; Seedevi, P.; Abirami, R.G.; Rajan, D.K. Application of marine-derived polysaccharides as immunostimulants in aquaculture: A review of current knowledge and further perspectives. Fish Shellfish. Immunol. 2019, 86, 1177-1193. [CrossRef] [PubMed]

23. Aranaz, I.; Acosta, N.; Civera, C.; Elorza, B.; Mingo, J.; Castro, C.; Gandía, M.L.L.; Heras Caballero, A. Cosmetics and Cosmeceutical Applications of Chitin, Chitosan and Their Derivatives. Polymers 2018, 10, 213. [CrossRef] [PubMed]

24. Jiang, Z.; Li, H.; Qiao, J.; Yang, Y.; Wang, Y.; Liu, W.; Han, B. Potential Analysis and Preparation of Chitosan Oligosaccharides as Oral Nutritional Supplements of Cancer Adjuvant Therapy. Int. J. Mol. Sci. 2019, 20, 920. [CrossRef] [PubMed]

25. Song, Z.; Li, G.; Guan, F.; Liu, W. Application of Chitin/Chitosan and Their Derivatives in the Papermaking Industry. Polymers 2018, 10, 389. [CrossRef]

26. Rinaudo, M. Chitin and Chitosan Properties and Applications. Prog. Polym. Sci. 2006, 31, 603-632. [CrossRef]

27. Liu, S.; Sun, J.; Yu, L.; Zhang, C.; Bi, J.; Zhu, F.; Qu, M.; Jiang, C.; Yang, Q. Extraction and Characterization of Chitin from the Beetle Holotrichia parallela Motschulsky. Molecules 2012, 17, 4604-4611. [CrossRef]

28. Kaya, M.; Bağrıaçık, N.; Seyyar, O.; Baran, T. Comparison of chitin structures derived from three common wasp species (Vespa crabro Linnaeus, 1758, Vespa orientalis Linnaeus, 1771 and Vespula germanica (Fabricius, 1793)). Arch. Insect Biochem. Physiol. 2015, 89, 204-217. [CrossRef]

29. Sajomsang, W.; Gonil, P. Preparation and characterization of $\alpha$-chitin from cicada sloughs. Mater. Sci. Eng. C 2010, 30, 357-363. [CrossRef]

30. Kaya, M.; Mujtaba, M.; Bulut, E.; Akyuz, B.; Zelencova, L.; Sofi, K. Fluctuation in physicochemical properties of chitins extracted from different body parts of honeybee. Carbohydr. Polym. 2015, 132, 9-16. [CrossRef] 
31. Kaya, M.; Sofi, K.; Sargin, I.; Mujtaba, M. Changes in physicochemical properties of chitin at developmental stages (larvae, pupa and adult) of Vespa crabro (wasp). Carbohydr. Polym. 2016, 145, 64-70. [CrossRef]

32. Abo Elsoud, M.M.; El Kady, E.M. Current trends in fungal biosynthesis of chitin and chitosan. Bull. Natl. Res. Cent. 2019, 43, 59. [CrossRef]

33. Vasylchenko, O.; Abramova, M. Comparative analysis of sources for chitosan obtaining. Probl. Environ. Biotechnol. 2015, 1, 1-25. [CrossRef]

34. Feás Sánchez, X.; Charles, R.J. Notes on the Nest Architecture and Colony Composition in Winter of the Yellow-Legged Asian Hornet, Vespa velutina Lepeletier 1836 (Hym.: Vespidae), in Its Introduced Habitat in Galicia (NW Spain). Insects 2019, 10, 23737. [CrossRef]

35. Feás, X. Vespa velutina Spreading from 2 Nests to 10'642 in Just 4 Years in Northern Spain. 2017. Available online: https://www.vespavelutina.co.uk/vespavelutinanews/asian-hornet-spreading-from-2-nests-to-10642in-just-4-years-in-northern-spain (accessed on 25 April 2019).

36. Feás, $X$. The Asian Hornet (Vespa velutina nigrithorax): An exotic predator in Europe. What does the future hold? In Proceedings of the 42th British Beekeepers Association (BBKA) Spring Convention, Newport Shropshire, UK, 4 April 2019.

37. Kaya, M.; Mujtaba, M.; Ehrlich, H.; Salaberria, A.M.; Baran, T.; Amemiya, C.T.; Galli, R.; Akyuz, L.; Sargin, I.; Labidi, J. On chemistry of $\gamma$-chitin. Carbohydr. Polym. 2017, 176, 177-186. [CrossRef]

38. Jang, M.-K.; Kong, B.-G.; Jeong, Y.-I.; Lee, C.H.; Nah, J.-W. Physicochemical Characterization of $\alpha$-Chitin, $\beta$-Chitin, and $\gamma$-Chitin Separated from Natural Resources. J. Polym. Sci. Pol. Chem. 2004, 42, 3423-3432. [CrossRef]

39. Cardenas, G.; Cabrera, G.; Taboada, E.; Miranda, S. Chitin characterization by SEM, FTIR, XRD, and 13C cross polarization/mass angle spinning NMR. J. Appl. Polym. Sci. 2004, 93, 1876-1885. [CrossRef]

40. Muzzarelli, R. Native, Industrial, and Fossil Chitins; Jolles, P., Muzzarelli, R.A.A., Eds.; Chitin and Chitinases: Birkhauser, Switzerland, 1999; pp. 1-6.

41. Feás, X.; Seijas, J.A.; Vázquez-Tato, M.P.; Regal, R.; Cepeda, A.; Fente, C. Syntheses of molecularly imprinted polymers: Molecular recognition of cyproheptadine using original print molecules and azatadine as dummy templates. Anal. Chim. Acta 2009, 631, 237-244. [CrossRef]

42. Feás, X.; Ye, L.; Hosseini, S.V.; Fente, C.A.; Cepeda, A. Molecularly imprinted polyallylamine hydrogels: Another reassessment. Polym. Int. 2010, 59, 11-15. [CrossRef]

43. Feás, X.; Fente, C.A.; Hosseini, S.V.; Seijas, J.A.; Vázquez, B.I.; Franco, C.M.; Cepeda, A. Use of acrylic acid in the synthesis of molecularly imprinted polymers for the analysis of cyproheptadine. Mater. Sci. Eng. C 2009, 29, 398-404. [CrossRef]

44. Chandran, R.; Williams, L.; Hung, A.; Nowlin, K.; Lajeunesse, D. SEM characterization of anatomical variation in chitin organization in insect and arthropod cuticles. Micron 2016, 82, 74-85. [CrossRef]

45. Mathot, V.B.F. Calorimetry and Thermal Analysis of Polymers; Hanser Publisher: Munich, Germany, 1994.

46. Flynn, J.H. Degradation kinetics applied to lifetime predictions of polymers. Polym. Eng. Sci. 1980, 20, 675-677. [CrossRef]

47. Chen, J.; Wang, M.; Chi-Tang Ho, C.-T. Volatile Compounds Generated from Thermal Degradation of N-Acetylglucosamine. J. Agric. Food Chem. 1998, 46, 3207-3209. [CrossRef]

48. Wunderlich, B. Thermal Analysis; Academic Press Inc.: Cambridge, MA, USA, 1990.

49. Flynn, J.H. A critique of lifetime prediction of polymers by thermal analysis. Therm. Anal. 1995, 44, 499-512. [CrossRef]

50. Liaw, D.J.; Shen, W.C. Curing of acrylated epoxy resin based on bisphenol-S. Polym. Eng. Sci. 1994, 34, 1297-1303. [CrossRef]

51. Brown, M.E. Introduction to Thermal Analysis. In Technique and Applications; Chapman and Hall: London, UK, 1988.

52. Dollimore, D.; Gamlen, G.A.; Taylor, T.J. The effect of a pre-exponential function $A=A_{n} T^{n}$ on rising temperature kinetic parameter calculations. Thermochim. Acta 1982, 54, 181-186. [CrossRef]

53. Nuñez, L.; Lópex, F.F.; Grueiro, L.F.; Rodríguez, J.A. Activation energies and rate constants for an epoxy/cure agent reaction. Variation in peak exotherm temperature. J. Therm. Anal. Calorim. 1996, 47, 743-750. [CrossRef]

54. Criado, J.M.; Málek, J.; Ortega, A. Applicability of the master plots in kinetic analysis of non-isothermal data. Thermochim. Acta 1989, 147, 377-385. [CrossRef] 
55. Kissinger, H.E. Reaction Kinetics in Differential Thermal Analysis. Anal. Chem. 1957, 29, $1702-1706$. [CrossRef]

56. Flynn, J.H.; Wall, L.A. General treatment of the thermogravimetry of polymers. J. Res. Nat. Bur. Stand. A Phys. Chem. 1966, 70A, 487-523. [CrossRef]

57. Ozawa, T. A New Method of Analyzing Thermogravimetric Data. Bull. Chem. Soc. Jpn. 1965, 38, 1881-1886. [CrossRef]

58. Brown, M.E.; Galwey, A.K. Reaction in the Solid State, Comprehensive Chemical Kinetics; Elsevier: Amsterdam, The Netherlands, 1980; Volume 22.

59. Kassman, A.J. Evaluation and optimization of integral methods for the analysis of thermogravimetric data. Thermochim. Acta 1985, 84, 89-99. [CrossRef]

60. Doyle, C.D. Series Approximations to the Equation of Thermogravimetric Data. Nature 1965, 207, $290-291$. [CrossRef]

61. Coats, A.W.; Redfern, J.P. Kinetic Parameters from Thermogravimetric Data. Nature 1964, 201, 68-69. [CrossRef]

62. Kucukgulmez, A.; Celik, M.; Yanar, Y.; Sen, D.; Polat, H.; Kadak, A.E. Physicochemical characterization of chitosan extracted from Metapenaeus stebbingi shells. Food Chem. 2011, 126, 1144-1148. [CrossRef]

Sample Availability: Samples of the insects are available from the authors. 